\title{
Tripe palm: a paraneoplastic manifestation of gastric cancer
}

\author{
Wei-Ti Chen MD MS, Chia-Hui Chu MD
}

Cite as: CMAJ 2019 April 1;191:E366. doi: 10.1503/cmaj.181104

A

73-year-old man presented with a warty thickening of the skin on his hands and feet, which had been present for more than 1 year. He also reported general weakness, poor appetite and a weight loss of $8 \mathrm{~kg}$ over 6 months. The palms of his hands and soles of his feet had a rugose appearance with a ridged surface and exaggerated hyperlinear dermatoglyphics (Figure 1). The patient also had hyperpigmented and velvety papillomatosis of skinfolds on the groin and perianal regions (Figure 2A). We initially thought the skin lesions were related to diffuse cutaneous warts, and we performed a skin biopsy on the patient's left palm. Biopsy results showed hyperkeratosis, papillomatosis and marked acanthosis of the epidermis without cell atypia or koilocytosis (Appendix 1, available at www.cmaj.ca/lookup/suppl/doi:10.1503/cmaj.181104/-/DC1). On the basis of the biopsy results and the patient's clinical presentation, we diagnosed tripe palm.

Because tripe palm is associated with malignancy in $90 \%$ of cases, $, 1,2$ we conducted a malignancy survey, including abdominal computed tomography (Figure 2B) and upper gastrointestinal tract endoscopy, which showed submucosal tumours involving gastric cardia. We later diagnosed gastric adenocarcinoma on the basis of histopathology findings.

Tripe palm is considered a paraneoplastic phenomenon. It can present alone or occur concomitantly with other cutaneous paraneoplastic syndromes, of which acanthosis nigricans is observed $70 \%$ of the time (Figure 2A). ${ }^{3}$ Gastric carcinoma is the most commonly associated cancer in patients presenting with both tripe palm and acanthosis nigricans, and lung carcinoma is the most frequent neoplasm in patients with only tripe palms. ${ }^{3,4}$ Identifying tripe palm and acanthosis nigricans may lead to earlier identification and treatment of primary malignancies.

\section{References}

1. Hejna M, Woll E, Tschandl P, et al. Cutaneous paraneoplastic disorders in stomach cancer: collaboration between oncologically active dermatologists and clinical oncologists. Crit Rev Oncol Hematol 2016;103:78-85.

2. Fabroni C, Gimma A, Cardinali C, et al. Tripe palms associated with malignant acanthosis nigricans in a patient with gastric adenocarcinoma: a case report and review of the literature. Dermatol Online J 2012;18:15.

3. Cohen PR, Grossman ME, Silvers DN, et al. Tripe palms and cancer. Clin Dermatol 1993;11:165-73.

4. Zhang N, Qian Y, Feng AP. Acanthosis nigricans, tripe palms, and sign of LeserTrelat in a patient with gastric adenocarcinoma: case report and literature review in China. Int J Dermatol 2015;54:338-42.

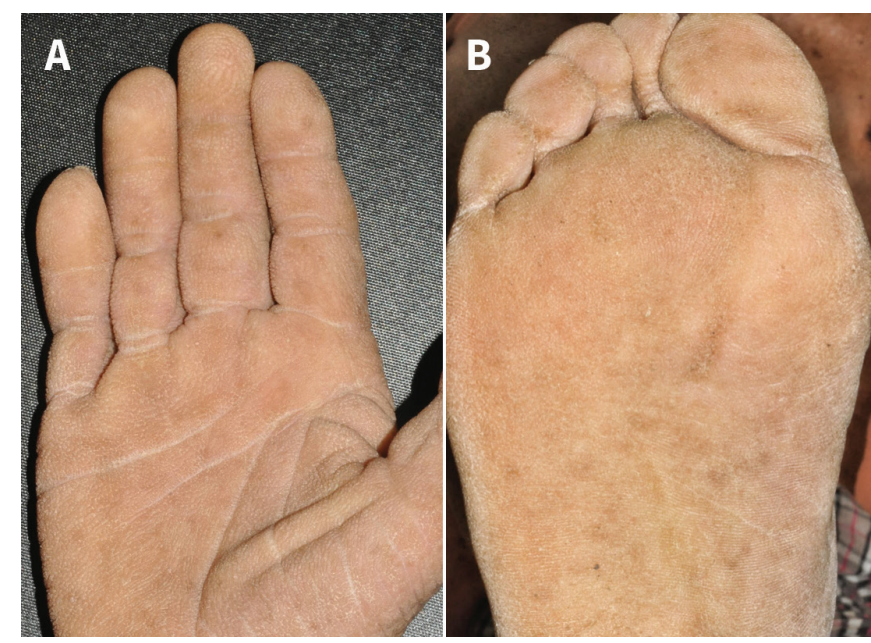

Figure 1: A rugose appearance with a ridged surface and exaggerated hyperlinear dermatoglyphics, mimicking the stomach lining or tripe of a ruminant, on the palms of the hands (A) and soles of the feet (B) in a 73-year-old man.

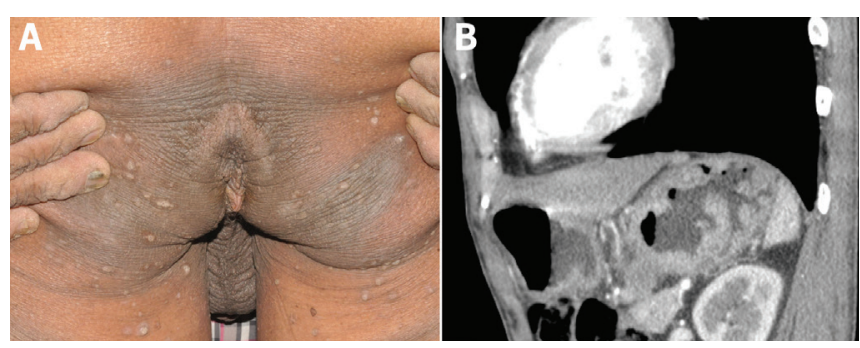

Figure 2: Hyperpigmented and velvety papillomatosis of skinfolds (acanthosis nigricans) on the groin and perianal regions (A) presented concomitantly with tripe palm in the patient. Contrast-enhanced abdominal computed tomography showed multiple submucosal tumours involving the gastric cardia (B).

\section{Competing interests: None declared.}

This article has been peer reviewed.

The authors have obtained patient consent.

Affiliations: Department of Dermatology (Chen), Chang Gung Memorial Hospital, Linkou; College of Medicine (Chen), Chang Gung University, Taoyuan, Taiwan; Department of Dermatology (Chu), Lotung Poh-Ai Hospital, Lotung, Yilan, Taiwan

Correspondence to: Chia-Hui Chu, Jorcy.nini@gmail.com 